\title{
A Fast, Reciprocal Pathway between the Lateral Geniculate Nucleus and Visual Cortex in the Macaque Monkey
}

\author{
Farran Briggs and W. Martin Usrey \\ Center for Neuroscience, University of California, Davis, Davis, California 95618
}

\begin{abstract}
Neurons in the lateral geniculate nucleus (LGN) not only provide feedforward input to primary visual cortex (V1), but also receive robust feedback from the cortex. Accordingly, visual processing in the LGN is continuously influenced by previous patterns of activity. This study examines the temporal properties of feedforward and feedback pathways between the LGN and V1 in the macaque monkey to provide a lower bound on how quickly the cortex can influence the LGN. In so doing, we identified a subclass of corticogeniculate neurons that receives direct, suprathreshold input from the LGN that is similar in latency to that directed to other recipient neurons $(4.2 \pm 0.4 \mathrm{vs}$ $4.0 \pm 0.2 \mathrm{~ms}$ ). These neurons also provide feedback to the LGN that is significantly shorter in latency than that supplied by corticogeniculate neurons lacking LGN input ( $5.1 \pm 1.3$ vs $11.1 \pm 2.3 \mathrm{~ms}$, respectively). Across our sample of corticogeniculate neurons, the shortest combined visual response latency and feedback latency was $37 \mathrm{~ms}$ (mean, $52.5 \pm 3.8 \mathrm{~ms}$ ), indicating that visual signals can rapidly travel from the periphery to the cortex and back to the LGN.
\end{abstract}

Key words: V1; LGN; primate; temporal; corticogeniculate; vision

\section{Introduction}

A reciprocal arrangement of feedforward and feedback projections interconnects the thalamus and cerebral cortex. In the visual system, the feedforward pathway from the lateral geniculate nucleus (LGN) provides the primary visual cortex (V1) with visual information coming from the retina. Feedback projections from V1 then complete the loop, because axons from corticogeniculate neurons project directly back to the LGN. Such architecture allows each pathway to dynamically influence the other. To develop realistic models of the nature of this influence, it is important to know how fast activity can propagate in the feedforward and feedback directions, as well as the shortest circuit required for linking the feedforward and feedback pathways. This study provides the first account of how quickly signals can traverse the geniculo-corticogeniculate loop in the primate.

In the primate, magnocellular and parvocellular LGN neurons give rise to axons that terminate most densely in layer $4 \mathrm{C}$ of the V1 and less densely in layer 6 (Hubel and Wiesel, 1972; Hendrickson et al., 1978; Blasdel and Lund, 1983). Corticogeniculate feedback arises exclusively from neurons with cell bodies in layer 6 (Lund et al., 1975; Hendrickson et al., 1978; Fitzpatrick et al., 1994). Because many layer 6 neurons have apical dendrites that branch within layer $4 \mathrm{C}$ and basal dendrites that branch within layer 6, they have the opportunity to receive direct LGN input both within layer 4C and layer 6 (Lund and Boothe, 1975; Wiser and Callaway, 1996). However, because corticogeniculate neu-

Received Jan. 5, 2007; revised April 16, 2007; accepted April 19, 2007

This work was supported by National Institutes of Health Grants EY13588 and EY15580, the McKnight Foundation, and the Esther A. and Joseph Klingenstein Fund.

Correspondence should be addressed to W. Martin Usrey, Center for Neuroscience, University of California, Davis, Davis, CA 95618. E-mail: wmusrey@ucdavis.edu.

DOI:10.1523/JNEUROSCI.1035-07.2007

Copyright $\odot 2007$ Society for Neuroscience $\quad$ 0270-6474/07/275431-06\$15.00/0 rons comprise only a small fraction of layer 6 neurons in the primate (14\%) (Fitzpatrick et al., 1994), it is not clear that they actually receive direct LGN input or that LGN input, if present, can drive responses. In the cat, where LGN input to layer 6 may differ in density compared with the primate, physiological studies report that all layer 6 neurons, including corticogeniculate neurons, receive subthreshold geniculocortical input that rarely drives suprathreshold spikes (Ferster and Lindstrom, 1983). In the macaque monkey, $\sim 50 \%$ of layer 6 neurons receive suprathreshold input from the LGN (Bullier and Henry, 1980); whether or not corticogeniculate neurons are included among these neurons remains to be determined.

To examine the temporal properties of feedforward and feedback transmission between the LGN and V1 as well as the prevalence of LGN input onto corticogeniculate neurons, we recorded single-unit activity in $\mathrm{V} 1$ of anesthetized and alert macaque monkeys while evoking orthodromic and antidromic spikes with electrical stimulation in the LGN. Our results reveal a distinct subclass of corticogeniculate neurons that receive direct, fast suprathreshold geniculocortical input. These corticogeniculate neurons also give rise to feedback that is significantly faster than that supplied by the rest of the corticogeniculate population. These results demonstrate that visual signals can propagate rapidly from the periphery to the cortex and back to the LGN.

\section{Materials and Methods}

Eight adult male macaque monkeys (Macacca mulatta) were used in this study. Seven animals were used for anesthetized recordings and one for alert recordings. All procedures conformed to National Institutes of Health guidelines and were approved by the Animal Care and Use Committee at the University of California, Davis.

Surgical procedures. Animals for anesthetized recordings were initially anesthetized with ketamine $(10 \mathrm{mg} / \mathrm{kg}, \mathrm{i} . \mathrm{m}$.) and maintained with sufentanil citrate (3-6 $\mu \mathrm{g} / \mathrm{kg} / \mathrm{h}$, i.v.), isoflurane ( $0.5 \%)$, and nitrous oxide (1:2, 
in oxygen). Temperature, expired $\mathrm{CO}_{2}$, electrocardiogram (ECG), electroencephalogram (EEG), heart rate, and arterial oxygen saturation were monitored continuously. Proper anesthetic depth was assessed by monitoring the EEG for changes in slow-wave/spindle activity and the ECG and expired $\mathrm{CO}_{2}$. If changes in any of these measures indicated a decreased level of anesthesia, additional sufentanil was given and the rate of infusion increased. Craniotomies were made over the LGN and V1 and the dura was reflected. The eyes were fitted with contact lenses and focused on a tangent screen located $172 \mathrm{~cm}$ in front of the animal. Once all surgical procedures were complete, animals were paralyzed with vencuronium bromide $(0.2 \mathrm{mg} / \mathrm{kg} / \mathrm{h}$, i.v. $)$.

Under full surgical anesthesia, the animal used for alert recordings was equipped with a scleral eye coil and a cranial implant containing a head restraint post and two recording cylinders, one over the LGN and one over V1.

Neuronal recordings, electrical stimulation, and visual stimuli. Singleunit responses from V1 of alert and anesthetized animals were recorded to a PC with a Power 1401 acquisition system and Spike2 software (Cambridge Electronic Design, Cambridge, UK). While recording from a V1 neuron, geniculocortical and corticogeniculate axons were stimulated electrically via one or two platinum/iridium electrodes implanted in the LGN. Stimulating electrodes(s) were positioned in retinotopic register with the cortical electrodes and the $500 \mu \mathrm{m}$ exposed tips spanned multiple layers. Stimulating electrodes were connected to an AM Systems (Carlsborg, WA) isolated pulse stimulator that delivered a brief, biphasic shock $(0.2 \mathrm{~ms} ; \sim 10 \mathrm{~V})$ in one of two modes: a noncollision mode where shocks were delivered at regular intervals (every $5 \mathrm{~s}$ ), or a collision mode where shocks were triggered to occur within $1 \mathrm{~ms}$ of a spontaneous spike from the cortical neuron.

Visual stimuli were generated with a VSG2/5 system (Cambridge Research Systems, Rochester, UK) and presented on a Sony (Tokyo, Japan) monitor with a refresh rate of $140 \mathrm{~Hz}$ and a mean luminance of $38 \mathrm{~cd} / \mathrm{m}^{2}$. For recordings from the alert animal, stimuli were presented while the animal maintained fixation for fluid reward. Trials were aborted if eye position deviated by $>0.35^{\circ}$. Drifting sinusoidal gratings of optimal orientation, spatial frequency, and $70 \%$ contrast were used to characterize neurons according to the ratio of the fundamental harmonic (f1) to mean response (Skottun et al., 1991). For neurons with ratios $<1.0$ (and $>1000$ recorded spikes), visual response latency was determined from responses to the drifting sinusoidal stimulus.

Histology. In anesthetized animals, electrolytic lesions ( $4 \mu \mathrm{A} ; 4 \mathrm{~s})$ were made to reconstruct the locations of recording sites. At the end of experiments, animals were killed with an overdose of sodium pentobarbital $(80 \mathrm{mg} / \mathrm{kg})$ and perfused with $4 \%$ paraformaldehyde. Tissue was sectioned on a freezing microtome and stained with thionin.

\section{Results}

We recorded single-unit responses in V1 of anesthetized and alert macaque monkeys while electrically stimulating the LGN to determine how quickly information can travel in the reciprocal pathways that interconnect the two structures. In particular, we were interested in determining (1) the time course of spike propagation in the geniculocortical and corticogeniculate pathways, (2) whether geniculocortical input can directly drive suprathreshold responses from corticogeniculate neurons, and (3) the time course of visual responses among corticogeniculate neurons. Geniculocortical recipient (GR) neurons and corticogeniculate (CG) neurons were identified both by the location of neuronal recordings (Fig. $1 B$ ) and by the responses evoked after brief electrical shocks in the LGN (Figs. 1A, 2).

Once a cortical neuron was identified that reliably produced a spike at a fixed latency after an electrical shock, a collision test was performed to determine whether the neuron was a GR neuron and/or a CG neuron. Figure 2 shows the responses of three representative cortical neurons. Although all three neurons reliably followed the electrical shock in the noncollision trials (blue traces), the neurons displayed different response patterns in the
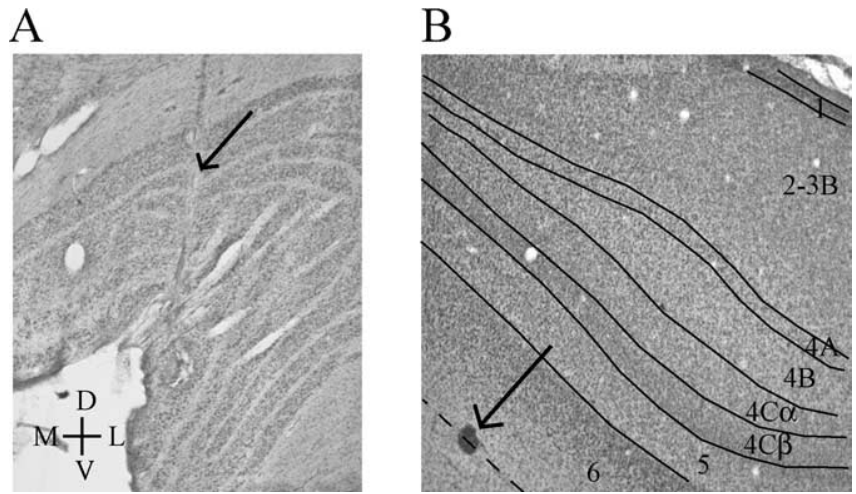

Figure 1. Location of stimulating electrodes and recording sites. $\boldsymbol{A}$, Nissl-stained section of the LGN showing the track lesion from the stimulating electrode (arrow). $\boldsymbol{B}$, Nissl-stained section of $\mathrm{V} 1$ showing a lesion (arrow) made at the recording site of a corticogeniculate neuron that did not receive LGN input. Dashed line represents the estimated layer $6 /$ white matter border. D, Dorsal; L, lateral; M, medial; V, ventral.

collision trials (red traces). In a collision trial, a spontaneous spike from the recorded cortical neuron triggers the electrical shock. If the neuron is a GR neuron that receives feedforward input from the LGN, then the spontaneous spike will not affect the propagation of the orthodromic spike and the neuron will produce a spike at the fixed latency, as in Figure $2 \mathrm{~A}$. However, if the neuron is a CG neuron that provides feedback to the LGN, then the spontaneous spike traveling toward the LGN will collide with the electrically evoked antidromic spike and the antidromic spike will not reach the cortex, as in Figure $2 B$. Finally, if the neuron is both a GR and a CG neuron (a GRCG neuron), then the neuron will produce two spikes during a noncollision trial (one orthodromic, the other antidromic), but just one spike (orthodromic) during a collision trial, as in Figure 2C.

In total, we recorded from $77 \mathrm{~V} 1$ neurons that reliably followed electrical stimulation in the LGN. Recordings were made from both alert and anesthetized animals to compare the activation latencies of neurons in the two preparations. Accordingly, 41 neurons were recorded from in the alert animal (25 GR, 11 CG, and 5 GRCG neurons) and 36 neurons were recorded from in anesthetized animals (17 GR, 15 CG, and 4 GRCG neurons). Importantly, there were no significant differences in the activation latencies between alert and anesthetized animals for GR, CG, and GRCG neurons ( $p=0.1-0.4, t$ tests).

Consistent with past results (Bullier and Henry, 1980), spike propagation in the geniculocortical pathway was fast, as the mean orthodromic latency among GR neurons was $4.0 \pm 0.2 \mathrm{~ms}$ (Fig. $3 A$, dashed line). Orthodromic latencies for GRCG neurons were similar with an average latency of $4.2 \pm 0.4 \mathrm{~ms}(p=0.3, t$ test $)$ (Fig. 3A), suggesting that LGN input directed to layers 4 and 6 follow a similar time course.

Antidromic latencies of CG neurons showed greater diversity (Fig. 3B). Although the mean antidromic latency of CG neurons was significantly greater than the mean orthodromic latency of GR neurons ( $9.5 \pm 1.7$ vs $4.0 \pm 0.2 \mathrm{~ms}$, respectively; $p<0.002, t$ test) (Fig. $3 A, B$, dashed lines), most CG neurons responded with short latencies. Notably, 21 of 35 CG and GRCG neurons (60\%) in our sample had antidromic latencies that were as fast as the orthodromic latencies measured from GR neurons. Interestingly, although the distribution of antidromic latencies of GRCG and CG neurons are partially overlapping, the antidromic latencies among GRCG neurons are significantly shorter than those for the remaining CG neurons (5.1 \pm 1.3 vs $11.1 \pm 2.3 \mathrm{~ms}$, respectively; 

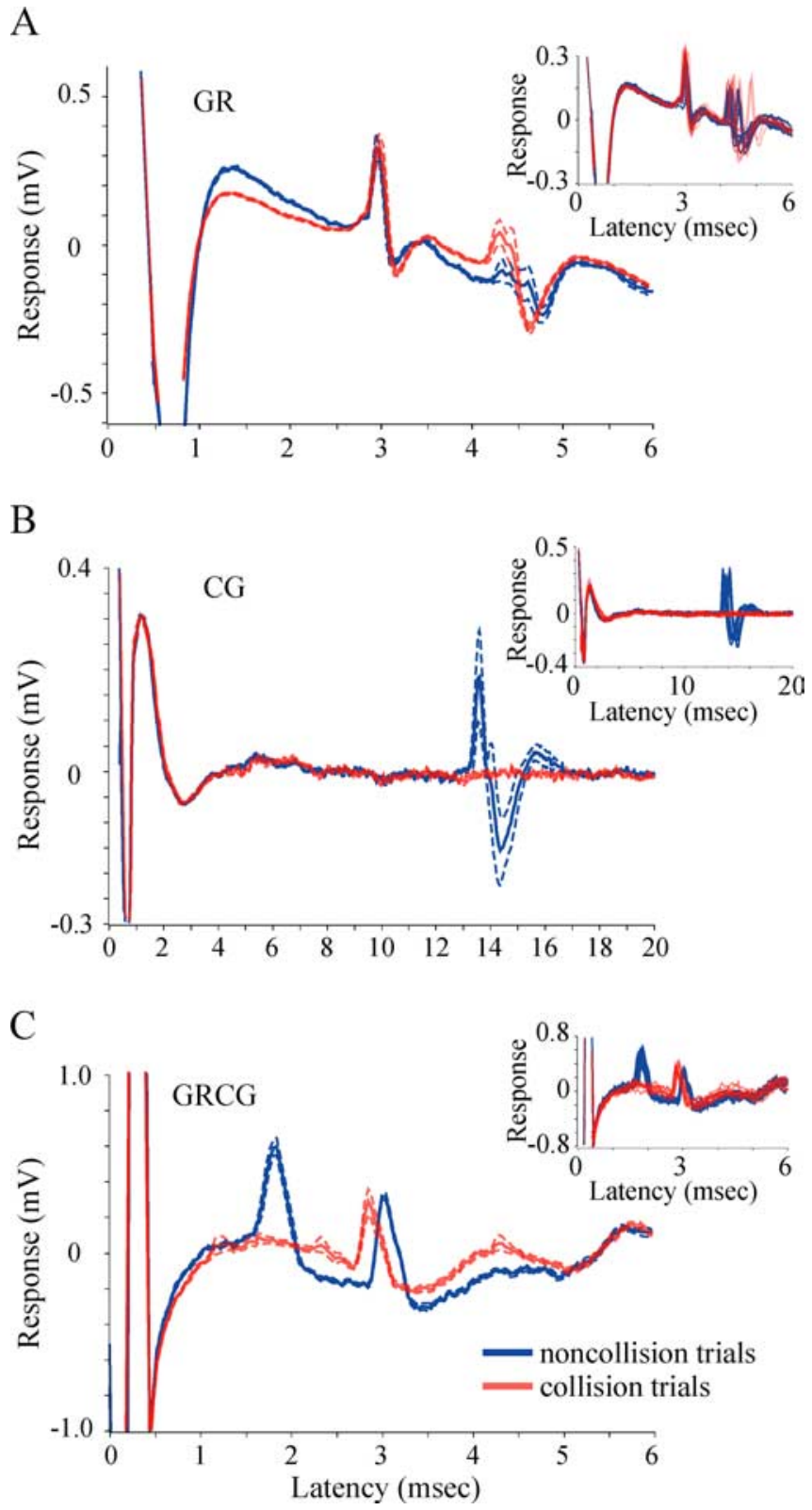

Figure 2. Responses of three representative cortical neurons to electrical stimulation in the LGN. In each panel, solid blue and red lines represent average responses to noncollision and collision trials, respectively (average of 12 trials; aligned to stimulus artifact at time 0 ). Dashed lines represent SEs. Insets show overlays of 7-10 responses. $\boldsymbol{A}$, Responses of a GR neuron. This neuron reliably fired spikes at a latency of $2.9 \mathrm{~ms}$ after LGN stimulation in noncollision and collision trials. $\boldsymbol{B}$, Responses of a $\mathrm{C} G$ neuron. This neuron had a latency of $13.7 \mathrm{~ms}$ in noncollision trials, but failed to fire spikes in collision trials. C, Responses of a GRCG neuron. This neuron fired two spikes at 1.6 and $2.8 \mathrm{~ms}$ in noncollision trials, but only one spike at $2.6 \mathrm{~ms}$ in collision trials.

$p=0.01, t$ test) (Fig. $3 B$ ). This suggests that GRCG neurons represent a distinct subclass of CG neurons, exhibiting fast orthodromic and antidromic latencies. Figure $3 C$ shows the distribution of orthodromic plus antidromic latencies for GRCG neurons. On average, the time required for spikes traveling in the reciprocal pathway from the LGN to GRCG neurons and back to the LGN was $9.3 \pm 1.6 \mathrm{~ms}$.

Given the diversity of conduction latencies among the feedback axons in our sample of CG neurons, we next asked whether there is a relationship between feedback latency and visual physiology. Using drifting grating stimuli, we found a range of $\mathrm{fl}$ : mean values with 13 of 17 neurons having values $<1.0$, indicating
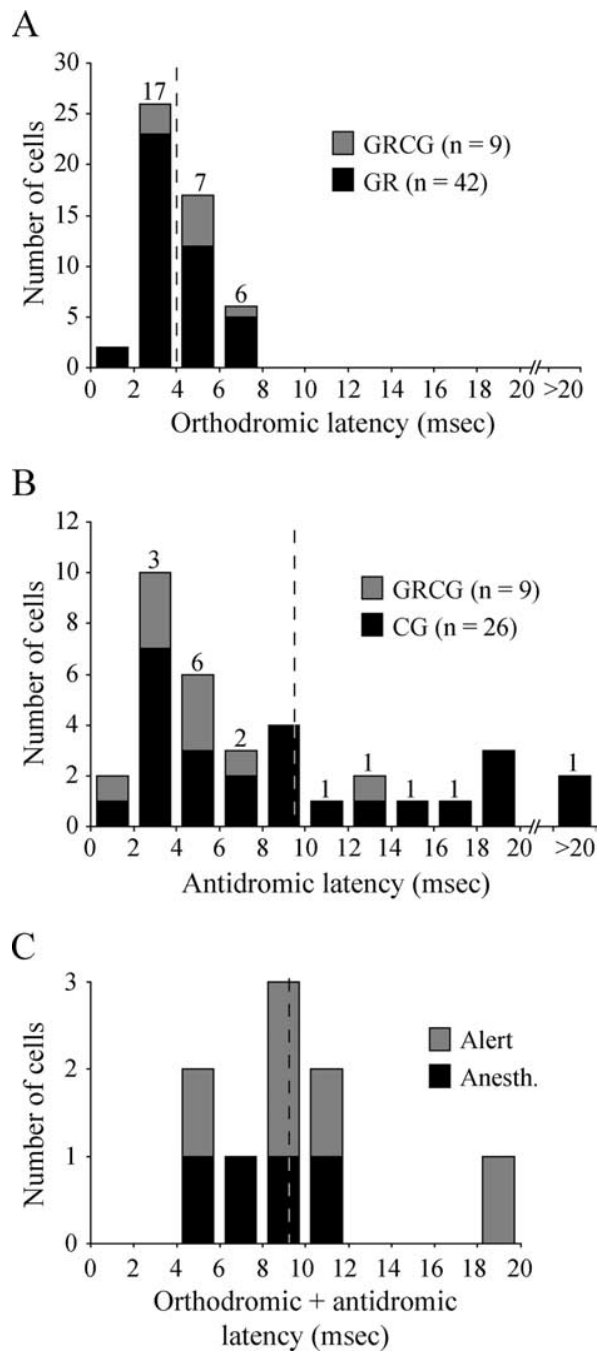

Figure 3. Orthodromic and antidromic latencies of $\mathrm{V} 1$ neurons. $A$, Histogram showing the distribution of orthodromic latencies for 51 geniculocortical recipient neurons: 42 GR neurons (black bars) and 9 GRCG neurons (gray bars). Numbers above each bar indicate neurons recorded in the alert animal. The mean latency for all geniculocortical recipient neurons was $4.0 \pm 0.2 \mathrm{~ms}$ (dashed line). B, Histogram showing the distribution of antidromic latencies for 35 corticogeniculate neurons: 26 CG neurons (black bars) and 9 GRCG neurons (gray bars). Numbers above each bar indicate neurons recorded in the alert animal. The mean latency for all corticogeniculate neurons was $9.5 \pm 1.7 \mathrm{~ms}$ (dashed line). C, Histogram showing the distribution of orthodromic plus antidromic latencies for nine GRCG neurons. Gray and black bars represent neurons recorded in alert and anesthetized animals, respectively. The mean combined latency was $9.3 \pm 1.6 \mathrm{~ms}$ (dashed line).

that complex cells represent the majority of neurons in our sample (Fig. 4A). Hartigan's dip test revealed that the sample was not multimodal $(p=0.98)$. Nevertheless, the antidromic latencies of neurons with fl:mean values $>1.0$ were significantly greater than those with values $<1.0(12.4 \pm 2.9$ vs $5.5 \pm 0.9 \mathrm{~ms} ; p=0.03, t$ test $)$. There was also a significant relationship between the antidromic latency and f1:mean response (Fig. $4 A)\left(R^{2}=0.83\right.$; $\left.p \ll 0.001\right)$.

To determine how quickly signals can propagate to V1 and back to the LGN after the onset of a visual stimulus, we measured the visual response latency of neurons with $\mathrm{fl}$ :mean values $<1.0$. This sample included both CG and GRCG neurons. The visually evoked responses of a representative CG and GRCG neuron are shown in Figure 4, $B$ and $C$. The firing rate of these neurons reached $50 \%$ of maximum response at 39 and $32 \mathrm{~ms}$ after stimulus onset (dashed lines). Across 11 GRCG and CG neurons, the 
A

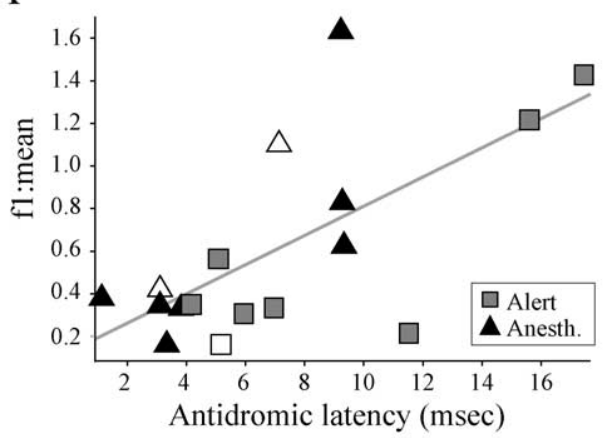

$\mathrm{B}$

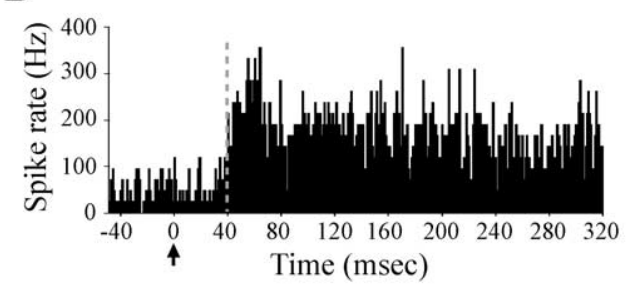

C

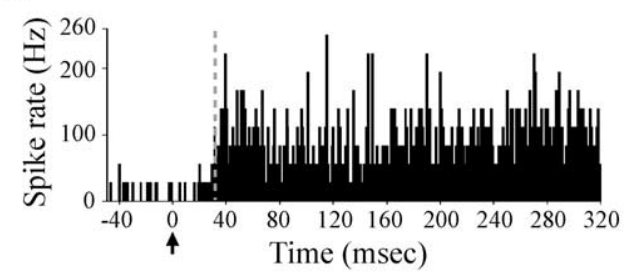

D

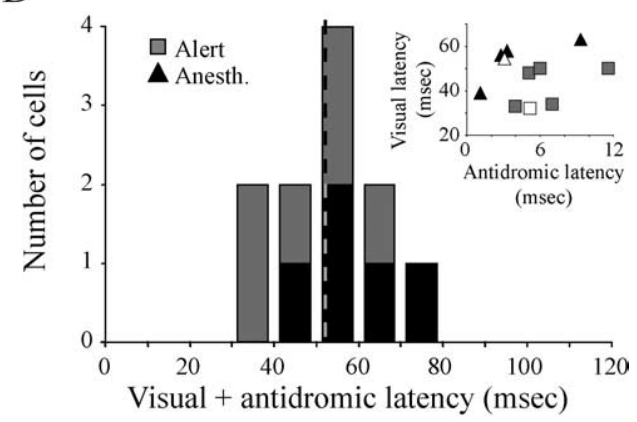

Figure 4. Visual physiology of corticogeniculate neurons. $A$, Relationship between f1:mean response and antidromic latency for 17 corticogeniculate neurons (open symbols indicate GRCG neurons). The gray line shows linear fit of the data. $B, C$, Peristimulus time histograms showing visual responses of a $C G$ and GRCG neuron, respectively. Arrows indicate onset of visual stimulation. Dashed lines represent time to reach $50 \%$ of maximum response (39 and $32 \mathrm{~ms}$ ). $\boldsymbol{D}$, Distribution of visual response plus antidromic latencies for 11 neurons (mean latency, $52.5 \pm$ $3.8 \mathrm{~ms}$; dashed line). The inset shows the relationship between visual response latency and antidromic latency. Gray and black symbols represent neurons recorded in alert and anesthetized animals, respectively. Open symbols indicate GRCG neurons.

mean latency to reach $50 \%$ of maximum response was $47.2 \pm 3.5$ ms (Fig. $4 D$, inset) (range, $32-63 \mathrm{~ms}$ ). By combining the visual response latency of these corticogeniculate neurons with the latency they require to conduct spikes back to the LGN (mean $5.3 \pm 1.0 \mathrm{~ms}$ ), we determined that corticogeniculate neurons can deliver feedback signals to the LGN as early as $37 \mathrm{~ms}$ after visual stimulus presentation (mean, $52.5 \pm 3.8 \mathrm{~ms}$ ) (Fig. $4 D$ ).

\section{Discussion}

Corticogeniculate neurons are in a strategic position to influence the processing of visual information as they give rise to axons that terminate both in the LGN and the layers of V1 that receive LGN input. Here, we provide the first report of the timing and visual physiology of corticogeniculate feedback in the primate. Our results reveal a subclass of corticogeniculate neurons that receives direct, suprathreshold input from the LGN and gives rise to feedback that is significantly faster than other corticogeniculate neurons. We also demonstrate that corticogeniculate feedback signals are delivered back to the LGN within $\sim 50 \mathrm{~ms}$ (range, 37-72 $\mathrm{ms}$ ) of the onset of a visual stimulus.

\section{Functional diversity of corticogeniculate neurons and implications for fast feedback}

Past studies in cats, ferrets, and rabbits have subdivided corticogeniculate neurons on the basis of antidromic activation latency (Tsumoto and Suda, 1980; Swadlow and Weyand, 1987; Briggs and Usrey, 2005) and/or visual responses (Tsumoto and Suda, 1980; Greive and Sillito, 1995; Hirsch et al., 1998). Our results from the monkey support the view that there are functionally distinct groups of corticogeniculate neurons. Consistent with results from cat and ferret (Tsumoto and Suda, 1980; Briggs and Usrey, 2005), we find a broad distribution of antidromic activation latencies and a significant relationship between latency and cell classification: corticogeniculate neurons with fast conducting axons are complex cells whereas those with slower axons tend to be simple cells. In addition, we show that corticogeniculate neurons can be grouped according to whether or not they receive direct, suprathreshold input from the LGN.

Although corticogeniculate axons are the single greatest source of synaptic input to the LGN, it is generally agreed that these axons have a modulatory, rather than driving, influence on LGN neurons (Guillery, 1969; Erisir et al., 1997; Crick and Koch, 1998; Sherman and Guillery, 1998). This modulatory influence need not be slow or follow a long time course, as results from the present study show that a subset of corticogeniculate neurons has axons with short conduction latencies. In addition, corticogeniculate synapses evoke postsynaptic currents that are mediated both by ionotropic and metabotropic glutamate receptors, suggesting that postsynaptic responses can be both fast and brief or longer lasting (Scharfman et al., 1990; McCormick and von Krosigk, 1992; Godwin et al., 1996a,b; von Krosigk et al., 1999).

Several functions for corticogeniculate feedback have been suggested over the years, including (1) sharpening the receptive fields of LGN neurons (Murphy and Sillito, 1987; Sillito and Jones, 2002; Webb et al., 2002), (2) adjusting the gain or timing of LGN responses (Molotchnikoff et al., 1984; Gulyas et al., 1990; Funke et al., 1996; Rao and Ballard, 1999; Przybyszewski et al., 2000), (3) shifting geniculate neurons between burst and tonic modes of firing (Sherman, 1996), and (4) increasing the correlated activity of LGN neurons (Sillito et al., 1994). Given the diversity of conduction latencies and response properties of corticogeniculate neurons, it seems likely that corticogeniculate neurons with different phenotypes contribute to different aspects of visual processing. Along these lines, because the subclass of corticogeniculate neurons that receive suprathreshold LGN input have short orthodromic and antidromic latencies, these neurons would seem particularly well suited for exerting an influence on the temporal properties of LGN responses.

\section{Identifying corticogeniculate neurons and geniculocortical recipient neurons}

We identified corticogeniculate neurons using electrical stimulation and a collision test. To reduce the possibility that we inadvertently excited cortical neurons with axons projecting to other 
subcortical targets, we placed stimulating electrodes in retinotopic register with cortical electrodes (to minimize stimulation parameters) and anatomically verified that cortical recordings were restricted to layer 6 , the only layer to contain corticogeniculate neurons (Lund et al., 1975; Hendrickson et al., 1978; Fitzpatrick et al., 1994).

We also used electrical stimulation to identify cortical neurons that receive input from the LGN. Although, in principle, cortical neurons could be driven by collaterals of antidromically activated corticogeniculate neurons, we believe the input recipient neurons in our sample were not collaterally driven. First, previous studies report that collateral activation of postsynaptic neurons requires higher-frequency stimulation than that used in this study $(>7 \mathrm{~Hz}$ compared with $<0.3 \mathrm{~Hz}$ ) (Ferster and Lindstrom, 1985). Second, unlike the reliable responses to stimulation that we measured, collateral activation does not reliably drive postsynaptic spikes (Ferster and Lindstrom, 1985). Third, compared with the synaptic currents associated with LGN input to layer 4 neurons, synaptic currents from the collaterals of layer 6 neurons are relatively small and inconsistent with the responses we observed (Stratford et al., 1996). Given these constraints, it seems unlikely that we have mislabeled the geniculocortical recipient neurons in our sample.

\section{Concluding remarks}

Few pathways in the brain are as prominent, yet poorly understood, as the corticothalamic feedback pathway (for review, see Alitto and Usrey, 2003; Briggs and Usrey, 2007). Here, we have shown that corticogeniculate neurons in the macaque monkey are a diverse group of neurons that display a wide range of axonal conduction latencies. Within this group, we have identified a special subclass of corticogeniculate neurons that receives direct, suprathreshold input from the LGN. Thus, with a single synapse, these neurons bring together the feedforward and feedback pathways. By taking into account the visual response latency and conduction latency of corticogeniculate neurons, we estimate that their axons can deliver feedback signals to the LGN within $\sim 50$ $\mathrm{ms}$ of the presentation of a visual stimulus. In addition, the combined orthodromic and antidromic activation latency of these neurons is short, $<10 \mathrm{~ms}$. Because the time course of visual responses in both the LGN and V1 typically exceeds this value (Maunsell and Gibson, 1992), the evolution of visual responses in both structures is likely influenced by fast conducting corticogeniculate neurons. These results underscore the view that the feedforward and feedback pathways should not be viewed in isolation, but rather as members of a dynamic reciprocal circuit interconnecting the thalamus and cerebral cortex.

\section{References}

Alitto HJ, Usrey WM (2003) Corticothalamic feedback and sensory processing. Curr Opin Neurobiol 13:1-6.

Blasdel GG, Lund JS (1983) Termination of afferent axons in macaque striate cortex. J Neurosci 3:1389-1413.

Briggs F, Usrey WM (2005) Temporal properties of feedforward and feedback pathways between the thalamus and visual cortex in the ferret. Thalamus Relat Syst 3:133-139.

Briggs F, Usrey WM (2007) Corticothalamic circuits: structure and function. In: Encyclopedia of neuroscience, Ed 4. Elsevier, in press.

Bullier J, Henry GH (1980) Ordinal position and afferent input of neurons in monkey striate cortex. J Comp Neurol 193:913-935.

Crick F, Koch C (1998) Constraints on cortical and thalamic projections: the no-strong-loops hypothesis. Nature 391:245-250.

Erisir A, Van Horn SC, Sherman SM (1997) Relative numbers of cortical and brainstem inputs to the lateral geniculate nucleus. Proc Natl Acad Sci USA 94:1517-1520.
Ferster D, Lindstrom S (1983) An intracellular analysis of geniculo-cortical connectivity in area 17 of the cat. J Physiol (Lond) 342:181-215.

Ferster D, Lindstrom S (1985) Augmenting responses evoked in area 17 of the cat by intracortical axon collaterals of cortico-geniculate cells. J Physiol (Lond) 367:217-232.

Fitzpatrick D, Usrey WM, Schofield BR, Einstein G (1994) The sublaminar organization of corticogeniculate neurons in layer 6 of macaque striate cortex. Vis Neurosci 11:307-315.

Funke K, Nelle E, Li B, Worgotter F (1996) Corticofugal feedback improves the timing of retino-geniculate signal transmission. NeuroReport 7:2130-2134

Godwin DW, Van Horn SC, Eriir A, Sesma M, Romano C, Sherman SM (1996a) Ultrastructural localization suggests that retinal and cortical inputs access different metabotropic glutamate receptors in the lateral geniculate nucleus. J Neurosci 16:8181-8192.

Godwin DW, Vaughan JW, Sherman SM (1996b) Metabotropic glutamate receptors switch visual response mode of lateral geniculate nucleus cells from burst to tonic. J Neurophysiol 76:1800-1816.

Greive KL, Sillito AM (1995) Differential properties of cells in the feline primary visual cortex providing the corticofugal feedback to the lateral geniculate nucleus and visual claustrum. J Neurosci 15:4868-4874.

Guillery RW (1969) A quantitative study of synaptic interconnections in the dorsal lateral geniculate nucleus of the cat. Z Zellforsch 96:39-48.

Gulyas B, Lagae L, Eysel U, Orban GA (1990) Corticofugal feedback influences the responses of geniculate neurons to moving stimuli. Exp Brain Res 79:441-446.

Hendrickson AE, Wilson JR, Ogren MP (1978) The neuroanatomical organization of pathways between the dorsal lateral geniculate nucleus and visual cortex in the old world and new world primates. J Comp Neurol 182:123-136.

Hirsch JA, Gallagher CA, Alonso JM, Martinez LM (1998) Ascending projections of simple and complex cells in layer 6 of the cat striate cortex. J Neurosci 18:8086-8094.

Hubel DH, Wiesel TN (1972) Laminar and columnar distribution of geniculo-cortical fibers in the macaque monkey. J Comp Neurol 146:421-450.

Lund JS, Boothe R (1975) Interlaminar connections and pyramidal neuron organization in the visual cortex, area 17, of the macaque monkey. J Comp Neurol 159:305-334.

Lund JS, Lund RD, Hendrickson AE, Bunt AH, Fuchs AF (1975) The origin of efferent pathways from the primary visual cortex, area 17 , of the macaque monkey. J Comp Neurol 164:287-304.

Maunsell JH, Gibson JR (1992) Visual response latencies in striate cortex of the macaque monkey. J Neurophysiol 68:1332-1344.

McCormick DA, von Krosigk M (1992) Corticothalamic activation modulates thalamic firing through glutamate "metabotropic" receptors. Proc Natl Acad Sci USA 89:2774-2778.

Molotchnikoff S, Tremblay F, Lepore F (1984) The role of the visual cortex in response properties of lateral geniculate cells in rats. Exp Brain Res 53:223-232.

Murphy PC, Sillito AM (1987) Corticofugal feedback influences the generation of length tuning in the visual pathway. Nature 329:727-729.

Przybyszewski AW, Gaska JP, Foote W, Pollen DA (2000) Striate cortex increases contrast gain of macaque LGN neurons. Vis Neurosci 17:485-494.

Rao RP, Ballard DH (1999) Predictive coding in the visual cortex: a functional interpretation of some extra-classical receptive-field effects. Nat Neurosci 2:79-87.

Scharfman HE, Lu SM, Guido W, Adams PR, Sherman SM (1990) $\mathrm{N}$-methyl-D-aspartate receptors contribute to excitatory postsynaptic potentials of cat lateral geniculate neurons recorded in thalamic slices. Proc Natl Acad Sci USA 87:4548-4552.

Sherman SM (1996) Dual response modes in lateral geniculate neurons: mechanisms and functions. Vis Neurosci 13:205-213.

Sherman SM, Guillery RW (1998) On the actions that one nerve cell can have on another: distinguishing "drivers" from "modulators." Proc Natl Acad Sci USA 95:7121-7126.

Sillito AM, Jones HE (2002) Corticothalamic interactions in the transfer of visual information. Philos Trans R Soc Lond B Biol Sci 357:1739-1752.

Sillito AM, Jones HE, Gerstein GL, West DC (1994) Feature-linked synchronization of thalamic relay cell firing induced by feedback from the visual cortex. Nature 369:479-482.

Skottun BC, De Valois RL, Grosof DH, Movshon JA, Albrecht DG, Bonds AB 
(1991) Classifying simple and complex cells on the basis of response modulation. Vision Res 31:1079-1086.

Stratford KJ, Tarczy-Hornoch K, Martin KA, Bannister NJ, Jack JJ (1996) Excitatory synaptic inputs to spiny stellate cells in cat visual cortex. Nature 382:258-261.

Swadlow HA, Weyand TG (1987) Corticogeniculate neurons, corticotectal neurons, and suspected interneurons in visual cortex of awake rabbits: receptive-field properties, axonal properties, and effects of EEG arousal. J Neurophysiol 57:977-1001.

Tsumoto T, Suda K (1980) Three groups of cortico-geniculate neurons and their distribution in binocular and monocular segments of cat striate cortex. J Comp Neurol 193:223-236. von Krosigk M, Monckton JE, Reiner PB, McCormick DA (1999) Dynamic properties of corticothalamic excitatory postsynaptic potentials and thalamic reticular inhibitory postsynaptic potentials in thalamocortical neurons of the guinea-pig dorsal lateral geniculate nucleus. Neuroscience 91:7-20.

Webb BS, Tinsley CJ, Barraclough NE, Easton A, Parker A, Derrington AM (2002) Feedback from V1 and inhibition from beyond the classical receptive field modulates the responses of neurons in the primate lateral geniculate nucleus. Vis Neurosci 19:583-592.

Wiser AK, Callaway EM (1996) Contributions of individual layer 6 pyramidal neurons to local circuitry in macaque primary visual cortex. J Neurosci 16:2724-2739. 